\title{
Forty years of sports performance research and little insight gained
}

Several errors occurred in the "Data supplement" of this Feature article (BMJ 2012;345:e4797, doi:10.1136/bmj.e4797) by Carl Heneghan and colleagues. The corrections to these errors are listed below according to their page number in the supplement, but they also have the following implications for the text of the Feature article itself. The first sentence of the second paragraph should now read: "Of this list of 175 studies, we were able to critically review 105 studies (100 clinical trials) dating from 1971 through to 2012." In paragraphs four and 12, where the Feature refers to "106 studies" this should instead cite 105 studies. Finally, with the change in risk status of six studies in the supplement from high to moderate risk of bias, and the removal of one moderate study, the article should state that the proportion of low quality studies is $70 \%$ [not $76 \%$, as cited in the eighth paragraph].

Page 10: Galloway SD, Maughan RJ. The effects of substrate and fluid provision on thermoregulatory and metabolic responses to prolonged exercise in a hot environment. J Sports Sci 2000;18:339-51. Study type: "Randomized crossover" [not

"Non randomized crossover"]; Risk of bias: "Moderate" [not "High"].

Page 29: Venables MC, Shaw L, Jeukendrup AE, Roedig-Penman A, Finke M, Newcombe RG, et al. Erosive effect of a new sports drink on dental enamel during exercise. Med Sci Sports Exerc 2005;37:39-44. Study type: "Randomized cross over trial" [not "Non randomized cross over trial"]; Risk of bias: "Moderate" [not "High"].

Page 31: Gant, Williams \& Backhouse. The influence of carbohydrate-electrolyte solution on treadmill running performance. 2006. Supplement at a conference of European College of Sports Science. This work was never published.

Page 43: Rollo I, Williams C, Gant N, Nute M. The influence of carbohydrate mouth rinse on self-selected speeds during a 30-min treadmill run. Int J Sport Nutr Exerc Metab
2008;18:585-600. Study type: "Randomized cross over trial" [not "Cross over trial"]; Blinding status: "Blinded" [not "Lack of blinding"]; Risk of bias: "Moderate" [not "High"].

Page 44: Betts JA, Toone RJ, Stokes KA, Thompson D. Systemic indices of skeletal muscle damage and recovery of muscle function after exercise: effect of combined carbohydrate-protein ingestion. Appl Physiol Nutr Metab 2009;34:773-84. Blinding status: "Blinded" [not "Lack of blinding"]; Risk of bias: "Moderate" [not "High"].

Page 46: Foskett A, Ali A, Gant N. Caffeine enhances cognitive function and skill performance during simulated soccer activity. Int J Sport Nutr Exerc Metab 2009;19:410-23.This paper was not relevant to the product and so should not have appeared in the supplement (author communication).

Pages 49, 54: Rollo I, Cole M, Miller R, Williams C. Influence of mouth rinsing a carbohydrate solution on 1-h running performance. Med Sci Sports Exerc 2010;42:798-804. (Duplicate record.) Study type: Randomised controlled trial; Risk of bias: Moderate.

Page 52: Gant N, Ali A, Foskett A. The influence of caffeine and carbohydrate coingestion on simulated soccer performance. Int J Sport Nutr Exerc Metab 2010;20:191-7. Study type:

"Randomised crossover trial" [not "Non-randomised crossover trial"]; Blinding status: "Blinded" [not "Lack of blinding"]; Risk of bias: "Moderate" [not "High"].

Page 57: Rollo I, Williams C, Nevill M. Influence of ingesting versus mouth rinsing a carbohydrate solution during a 1-h run. Med Sci Sports Exerc 2011;43:468-75. Blinding status:

"Blinded" [not "Lack of blinding"]; Risk of bias: "Moderate" [not "High"].

Cite this as: BMJ 2012;345:e6085

๑ BMJ Publishing Group Ltd 2012 